\title{
Inhibitory Effects of Ginseng (Panax ginseng) Berry on Tumour Promotion and Inflammatory Ear Oedema Induced by TPA
}

\author{
Ken Yasukawa ${ }^{1, *}$, Wan-Kyunn Whang ${ }^{2}$ and Sung-Kwon Ko ${ }^{3}$ \\ ${ }^{1}$ School of Pharmacy, Nihon University, Chiba 274-8555, Japan \\ ${ }^{2}$ College of Pharmacy, Chung-Ang University, Seoul 156-756, Korea \\ ${ }^{3}$ Department of Oriental Medical Food \& Nutrition, Semyung University, Chungcheongbuk 390-711, Korea
}

\begin{abstract}
Cancer prevention is a major issue in the field of public health. Ethanol extracts of the ginseng berry were found to inhibit the inflammation induced by 12-O-tetradecanoylphorbol-13-acetate (TPA), a tumour promoter. The extracts also inhibited tumour promotion by TPA in the mouse skin two-stage carcinogenesis model. The major components, ginsenosides $\mathrm{Rd}(\mathbf{3})$ and $\mathrm{Re}(\mathbf{4})$, inhibited inflammation induced by TPA in mice, while protopanaxadiol (1) and protopanaxatriol (2), the aglycones of these ginsenosides, markedly inhibited TPA-induced inflammatory ear oedema in mice. The inhibitory effects of these compounds were more potent than those of indomethacin.
\end{abstract}

Keywords: Cancer chemoprevention, antitumour-promoting activity, two-stage carcinogenesis, ginsenosides, Panax ginseng.

\section{INTRODUCTION}

Cancer prevention is a major public health issue worldwide. We previously reported the inhibition of tumour promotion in mouse skin using components from plants and fungi $[1,2]$.

The root of Panax ginseng (Araliaceae), commonly called ginseng, is a genus of 11 species of slowgrowing perennial plants with fleshy roots. Ginseng is an ancient Taoist tonic herb, and has been used as a qi (vital essence) tonic in traditional Chinese medicine for about 5,000 years. The main medicinal species are now rare in the wild, but are cultivated commercially in Korea, China and Russia. Ginseng is taken internally for debilities associated with old age or illness, lack of appetite, insomnia, stress shock and chronic illness [3]. The constituents of ginseng roots are mainly triterpene saponins, sesquiterpenes, sterols, polyacetylenes and polysaccharides [4]. Many of the pharmacological effects documented for ginseng, at least in preclinical studies, directly oppose one another and this has been attributed to the effects of the individual ginsenosides. Protopanaxadiol-type ginsenosides exhibit central nervous system (CNS)-depressant, hypotensive and tranquillising actions, whilst protopanaxatriol-type ginsenosides exhibit CNS-stimulant, hypertensive and anti-fatigue actions. These opposing actions are thought to explain the adaptogenic reputation of ginseng; it is thought to increase the overall resistance

*Address correspondence to this author at the School of Pharmacy, Nihon University, Funabashi, Chiba 274-8555, Japan; Tel/Fax: +81 47465 1107;

E-mail: yasukawa.ken@nihon-u.ac.jp, yasukawa.ken@nihon-u.ne.jp of the body to stress and to balance bodily functions [5]. Ginseng has been approved as a non-prescription medicine in the European Union [6]. Christensen reviewed the pharmacological activity of ginsenosides [7]. Red ginseng extract reportedly suppresses tumour promotion in two-stage carcinogenesis in mice $[8,9]$. Total ginsenosides obtained from ginseng berries were also reported to be significantly more potent than those obtained from ginseng seeds [10].

In the present study, ginseng berry extracts were found to inhibit inflammatory ear oedema and tumour promotion induced by TPA in mouse skin, and aglycones of these ginsenosides more strongly inhibited TPA-induced ear oedema than indomethacin, an anti-inflammatory drug.

\section{MATERIALS AND METHODS}

\subsection{Analytical Methods}

Fast atom bombardment mass spectrometry (FABMS) was performed using a JEOL JMS-700 D mass spectrometer. ${ }^{13} \mathrm{C}$-nuclear magnetic resonance spectra was obtained on a Varian VNS $\left({ }^{13} \mathrm{C}, 150 \mathrm{MHz}\right)$ spectrometer. Pyridine- $d_{5}$ was used as the solvent, and tetramethyl silane was used as the internal standard. Column chromatography was carried out on Diaion HP20 (Mitsubishi Chemical Corp., Tokyo, Japan).

\subsection{Chemicals}

7,12-Dimethylbenz[a]anthracene (DMBA), indomethacin, and dimethyl sulfoxide (DMSO) were purchased from Sigma Chemical Co. (St. Louis, MO, 
USA). TPA was obtained from Chemical Cancer Research, Inc. (Minnesota, MN, USA). Methanol, ethanol, chloroform, ethyl acetate, $n$-butyl alcohol, acetone and $n$-hexane were purchased from Tokyo Kasei Kogyo Co., Ltd. (Tokyo, Japan).

\subsection{Material and Extraction}

Ginseng (Panax ginseng C. A. Meyer) berries were cultivated at Kimjae in Korea on July 14, 2007. The voucher specimen was deposited at the Oriental Medical Food Research Laboratory, Semyung University, Jecheon, Korea.

Ginseng berries were selected, dried and powdered. Exactly $4 \mathrm{~kg}$ of powdered samples were refluxed four times with $5 \mathrm{~L}$ of $95 \%$ ethyl alcohol for $2 \mathrm{~h}$ in a water bath. Extracts were filtered through filter paper (Nylon membrane filters 7404-004; Whatman, Dassel, Germany), and were concentrated in a vacuum evaporator.

The ethyl alcohol extract $(1 \mathrm{~kg})$ was suspended in water and extracted with diethylether three times using a separating funnel after removing lipid-soluble materials in the diethylether phase. The diethylether extract was $44 \mathrm{~g}$, and the water extract was $956 \mathrm{~g}$.

\subsection{Isolation}

The water extract (956 g) was subjected to column chromatography (C.C.) on Diaion HP-20 using water, $30 \%$ methanol, $50 \%$ methanol, $70 \%$ methanol and methanol, yielding 5 fractions; the water fraction (573.6 $\mathrm{g}$ ), the $30 \%$ methanol fraction $(133.8 \mathrm{~g})$, the $50 \%$ methanol fraction $(66.92 \mathrm{~g})$, the $70 \%$ methanol fraction $(114.7 \mathrm{~g})$ and the methanol fraction $(38.24 \mathrm{mg})$. The $50 \%$ methanol fraction $(66.0 \mathrm{~g})$ was then subjected to C.C. on silica gel using chloroform-methanol-water $(35: 15: 2)$ as an eluent to yield compound 1 (4.30 g), fraction $2(48.3 \mathrm{~g})$, fraction $3(9.05 \mathrm{~g})$ and fraction 4 $(4.60 \mathrm{~g})$, respectively. Fraction $2(48 \mathrm{~g})$ was subjected to HPLC (YMC C-18) using 65\% methanol to yield compound 2 (4.09 g), and fraction $3(9 \mathrm{~g})$ was subjected to HPLC (YMC C-18) using a 70\% methanol to yield compound $\mathbf{1}$ (750 $\mathrm{mg}$ ).

Compound 1, FAB-MS positive: 969.55 $\left(\left[M\left(\mathrm{C}_{48} \mathrm{H}_{82} \mathrm{O}_{18}\right)+\mathrm{Na}\right]^{+}\right)$, FAB-MS negative: $(945.55$ $\left.\left[M\left(\mathrm{C}_{48} \mathrm{H}_{82} \mathrm{O}_{18}\right)-\mathrm{H}\right]^{-}\right) .{ }^{13} \mathrm{C}-\mathrm{NMR} \quad \delta$ (pyridine- $\left.d_{5}\right)$ ppm: 130.74 (C-25), 125.72 (C-24), 105.76 (3-o-G-1), 104.89 (3-i-G-1), 98.06 (20-G-1), 88.77 (C-3), 83.12 (C-20), 83.12 (3-i-G-2), 79.00 (3-o-G-3), 78.09 (3-o-G-5), 78.09 (20-G-3), 78.09 (20-G-5), 77.89 (3-i-G-3), 77.70 (3-i-G-
5), 76.89 (3-o-G-2), 74.92 (20-G-2), 71.38 (3-o-G-4), 71.38 (20-G-4), 71.29 (3-i-G-4), 70.03 (C-12), 62.61 (20-G-6), 62.55 (3-i-G-6), 62.43 (3-o-G-6), 56.17 (C-5), 51.47 (C-17), 51.20 (C-14), 49.95 (C-9), 49.20 (C-13), 39.79 (C-8), 39.48 (C-4), 38.94 (C-1), 36.66 (C-10), 35.87 (C-22), 35.53 (C-7), 30.56 (C-11), 30.56 (C-15), 27.88 (C-28), 26.53 (C-16), 26.41 (C-2), 25.59 (C-26), 23.05 (C-23), 22.22 (C-21), 18.20 (C-6), 17.59 (C-27), 17.14 (C-30), 16.39 (C-29), 16.09 (C-18), 15.74 (C-19).

Compound 2, FAB-MS positive: 969.54 $\left(\left[M\left(\mathrm{C}_{48} \mathrm{H}_{82} \mathrm{O}_{18}\right)+\mathrm{Na}\right]^{+}\right)$, FAB-MS negative: 945.54 $\left.\left(\left[M\left(\mathrm{C}_{48} \mathrm{H}_{82} \mathrm{O}_{18}\right)-\mathrm{H}\right]\right]^{-}\right) .{ }^{13} \mathrm{C}-\mathrm{NMR} \quad \delta$ (pyridine- $\left.d_{5}\right) \quad$ ppm: 129.49 (C-25), 124.56 (C-24), 100.442 (6-G-1), 100.441 (6-R-1), 96.86 (20-G-1), 81.85 (C-20), 77.99 (6-G-2), 77.80 (20-G-3), 77.19 (C-3), 76.98 (20-G-5), 76.90 (6-G-3), 76.83 (6-G-5), 73.75 (20-G-2), 73.17 (C6), 72.75 (6-R-4), 71.16 (6-R-2), 71.01 (6-R-3), 70.87 (6-G-4), 70.19 (20-G-4), 68.77 (C-12), 68.06 (6-R-5), 61.66 (6-G-6), 61.43 (20-G-6), 61.43 (C-5), 50.27 (C17), 50.00 (C-14), 48.14 (C-9), 47.66 (C-13), 44.53 (C7), 39.78 (C-8), 38.58 (C-4), 38.24 (C-1), 37.98 (C-10), 34.61 (C-22), 29.53 (C-28), 29.33 (C-11), 29.33 (C-15), 26.34 (C-2), 25.22 (C-16), 24.35 (C-26), 21.82 (C-23), 20.90 (C-21), 17.34 (6-R-6), 16.35 (C-27), 16.22 (C19), 16.10 (C-18), 15.87 (C-29) , 15.81 (C-30).

\subsection{Animals}

Experiments were performed in accordance with the Guidelines of the Institutional Animal Care and Use Committee of the School of Pharmacy, Nihon University, Chiba, Japan. Female ICR mice were obtained from Japan SLC Inc., Shizuoka, Japan. The animals were housed in an air-conditioned, specificpathogen-free room $\left(24 \pm 2^{\circ} \mathrm{C}\right)$ lit from 08:00 to 20:00. Food and water were available ad libitum.

\subsection{TPA-Induced Inflammation}

TPA $(1 \mu \mathrm{g})$ dissolved in acetone $(20 \mu \mathrm{L})$ was applied to the right ear of the ICR mice using a micropipette. The same volume $(10 \mu \mathrm{L})$ was applied to both inner and outer surfaces of the ear. Test samples or their vehicles [chloroform-methanol (1:1) or chloroform-methanol-water $(1: 2: 1)$ ] used as controls, were topically applied about 30 min before the TPA treatment. For ear thickness determination, a pocket thickness gauge (Mitsutoyo Co., Ltd., Tokyo, Japan) with a range of $0-9 \mathrm{~mm}$, graduated at $0.01-\mathrm{mm}$ intervals and modified to increase the contact surface area to reduce tension, was applied to the tip of the ear. Ear thickness was determined before the TPA 
treatment (a), and oedema was measured at $6 \mathrm{~h}$ after the TPA treatment (b: TPA with vehicle; $b$ ': TPA with sample).

The following values were then calculated:

Oedema A = oedema induced by TPA with vehicle $(b-a)$;

Oedema $B=$ oedema induced by TPA with sample $\left(b^{\prime}-a\right)$;

Inhibition ratio $(\%)=[($ oedema $\mathrm{A}-$ oedema $\mathrm{B}) /$ oedema $\mathrm{A}] \times$ 100.

Each value was calculated as the mean of individual determinations from four mice.

\subsection{Two-Stage Carcinogenesis Experiments}

The backs of the mice (age, 7 weeks) were shaved using electric clippers once a week to remove hair. DMBA and TPA were dissolved in acetone and applied to the shaved area in a volume of $100 \mu \mathrm{L}$ using a micropipette. The initiation was accomplished by a single topical application of $50 \mu \mathrm{g}$ of DMBA. Promotion using $1 \mu \mathrm{g}$ of TPA, applied two times a week, was started one week after the initiation. The ethanol extract of the ginseng berry $(1.0 \mathrm{mg} / \mathrm{mouse})$ or its vehicle, acetone-DMSO-water $(8: 1: 1,100 \mu \mathrm{L})$, was topically applied $30 \mathrm{~min}$ before each TPA treatment. The number and diameter of skin tumours were determined every week, and the experiment was continued for 20 weeks. The experimental and control groups consisted of 15 mice each.

\subsection{Statistical Analysis}

The $50 \%$ inhibitory dose $\left(\mathrm{ID}_{50}\right)$ values and $95 \%$ confidence intervals $(95 \% \mathrm{Cl})$ were calculated by nonlinear regression using GraphPad Prism v. 5.0 (GraphPad Software, Inc., La Jolla, CA, USA). Differences between experimental groups were compared using Student's $t$-test and Mann-Whitney $U$ exact test.

\section{RESULTS AND DISCUSSION}

The ethanol extract from ginseng berries was evaluated for anti-inflammatory activity against TPAinduced inflammation in mice. This extract inhibited inflammation by $72 \%$ at $1.0 \mathrm{mg} / \mathrm{ear}$. The inhibitory effects against TPA-induced inflammation have been demonstrated to closely parallel those of the inhibition of tumour promotion in two-stage carcinogenesis initiated by DMBA and then by TPA, a well-known tumour promoter, in a mouse skin model [11]. The inhibitory effects of the ethanol extract of ginseng berry in a two-stage carcinogenesis test on mouse skin using DMBA as an initiator and TPA as a tumour promoter were then investigated. Figure $\mathbf{1 A}$ shows the time course of skin tumour formation in the groups treated with DMBA plus TPA, with or without the ethanol extract of ginseng berry. The first tumour appeared at week 5 in the group treated with DMBA plus TPA, and all 15 mice had tumours at week 12 . In the group treated with DMBA plus TPA and ethanol extract of ginseng berry, the first tumour appeared at week 10 . The percentage of tumour-bearing mice treated with DMBA plus TPA and ethanol extract of ginseng berry was $40 \%$ at week 20 . Figure 1B shows the average number of tumours per mouse. The group treated with DMBA plus TPA produced 11.2 tumours per mouse at week 20; the group treated with DMBA plus TPA and ethanol extract of ginseng berry had 1.7 tumours per mouse. Treatment with ethanol extract of ginseng berry caused an $85 \%$ reduction in the average number of tumours per mouse at week 20. On comparison with ethanol extracts of supplemental foods on tumour promotion, ginseng berry showed similar in activity as safflower [12], galangal [13] and gymnema [14].

Active components (1 and $\mathbf{2}$ ) were then isolated from the fractions of the ethanol extract of ginseng berry, and were identified based on various spectral data as ginsenoside $R d(3)$ [15] and ginsenoside $\operatorname{Re}(4)$ (Figure 2) [16], respectively. As shown in Table 1, the $\mathrm{ID}_{50}$ values for these compounds against TPA-induced inflammation were 232 and $231 \mathrm{nmol} /$ ear, respectively. In comparison with standard drugs, these ginsenosides were more effective than indomethacin $\left(\mathrm{ID}_{50}: 908\right.$ $\mathrm{nmol} / \mathrm{ear}$ ), an anti-inflammatory drug. We also tested the activity of the aglycons protopanaxadiol (1) and protopanaxatriol (2), and found that they markedly inhibited TPA-induced inflammation in mice.

Cytokines, chemokines and eicosanoids are inflammatory mediators known to play an important role in the promotion phase of carcinogenesis [17]. The proinflammatory cytokine tumour necrosis factor (TNF)$\alpha$ is the most important mediator of inflammation and is a well-known endogenous tumour promoter, as previous findings have shown that mice deficient in TNF- $\alpha$ have fewer skin tumours after DMBA and TPA application [18]. Most tumour-promoting agents and stimuli such as oxidative stress, TNF- $\alpha$ and lipopolysaccharides (LPS) induce activation of nuclear factor (NF)-KB [19]. Although different signalling cascade components have been found to be involved in the promotional stages of cancer development, those 

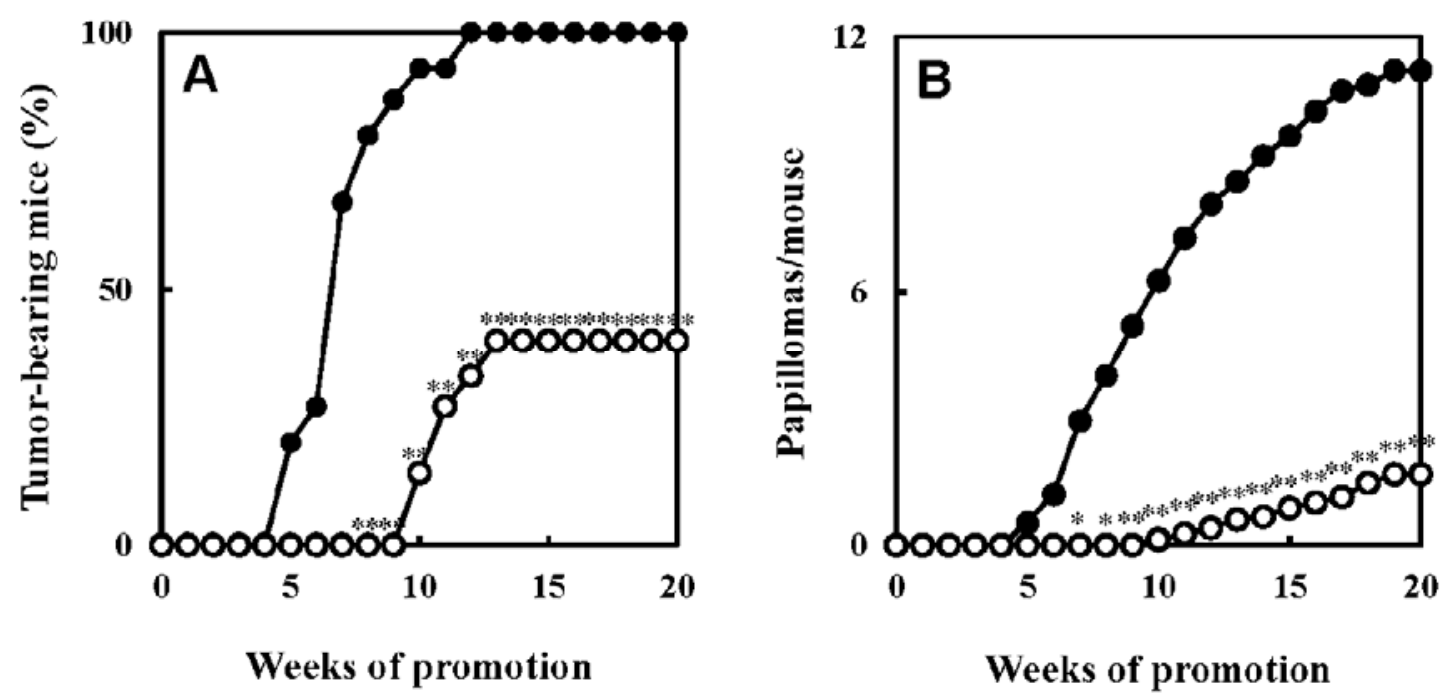

Figure 1: Inhibitory effects of ethanol extract of ginseng berry on tumour promotion in two-stage carcinogenesis in mouse skin.

From one week after initiation with a single topical application of $50 \mu \mathrm{g}$ of DMBA, $1 \mu \mathrm{g}$ of TPA was applied twice weekly. Topical application of ethanol extract of ginseng berry $(1 \mathrm{mg})$ or its vehicle was performed 30 min before each TPA treatment. Data are expressed $(\mathbf{A})$ as the percentage of mice bearing papillomas, and (B) as the average number of papillomas per mouse. $\bullet$ : TPA with vehicle; $\circ$ : TPA with ethanol extract of ginseng berry. ${ }^{*} p<0.05,{ }^{\star *} p<0.01$ compared with Mann-Whitney $U$ exact test $(\mathbf{A})$ and Student's $t$-test (B).

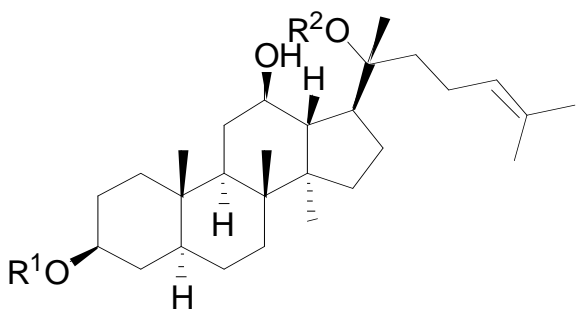

$\begin{array}{ccc} & \mathrm{R}^{1} & \mathrm{R}^{2} \\ 1 & \mathrm{H} & \mathrm{H} \\ 3 & \text { Glc } & \text { Glc } \\ & \text { Glc } & \end{array}$

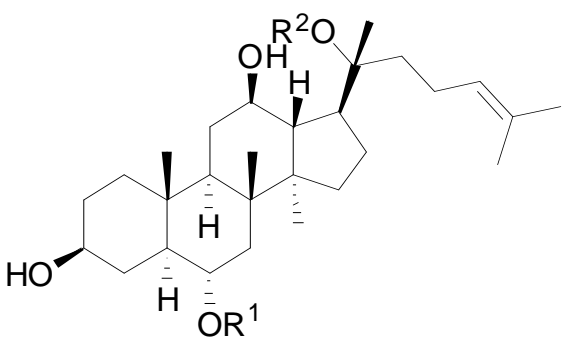

$\begin{array}{llll} & \mathrm{R}^{1} & \mathrm{R}^{2} \\ \mathbf{4} & \mathrm{H} & \mathrm{H} \\ & \text { Glc } & \text { Glc } \\ & \text { Rha } & \end{array}$

Figure 2. Chemical structures of ginsenosides $\mathrm{Rd}(\mathbf{3})$ and $\mathrm{Re}(\mathbf{4})$ from ginseng berry, and their aglycones (1-2).

Table 1: Inhibitory Effects of Ginsenosides from Ginseng Berry and their Aglycones on TPA-Induced Inflammatory Ear Oedema

\begin{tabular}{|c|c|c|}
\hline Compound & $I_{50}$ & n5\% Cl \\
\cline { 2 - 4 } & 205 & $135-315$ \\
\hline \hline Protopanaxadiol (1) & 153 & $120-196$ \\
\hline Protopanaxatriol (2) & 232 & $173-312$ \\
\hline Ginsenoside Rd (3) & 231 & $170-315$ \\
\hline Ginsenoside Re (4) & 908 & $755-1092$ \\
\hline Indomethacin & & \\
\hline
\end{tabular}

$\mathrm{ID}_{50}: 50 \%$ Inhibitory dose. $95 \% \mathrm{Cl}: 95 \%$ Confidence intervals.

that involve NF-KB are known to mediate inflammatory responses and to play a prominent role in tumour promotion [20]. One of the downstream targets of NF-
$\mathrm{KB}$ is cyclooxygenase (COX)-2, which plays a central role in inflammation. Uncontrolled expression of COX-2 has been observed in different premalignant and 
malignant stages [21]. Cells or tissues exposed to inflammatory stimuli such as tumour promoters, cytokines, endotoxins and reactive oxygen tends to show transcriptional up-regulation of COX-2 [22].

Wu et al. found that the ginsenosides $\mathrm{Rd}$ and $\mathrm{Re}$ were able to inhibit LPS-induced nitric oxide (NO) formation and TNF- $\alpha$ production due to inhibition of NF$\mathrm{KB}$ in N9 microglial cells [23]. These findings suggest that inhibition of LPS-induced NO formation and TNF- $\alpha$ production in microglia by ginsenosides is due to inhibition of NF-kB. The ginsenoside Rd selectively produces prostaglandin (PG)- $\mathrm{E}_{2}$ through COX-2 expression and this COX-2 induction by $R d$ is dependent on CCAAT/enhancer-binding protein (C/EBP) and AMP response element-binding protein (CREB) activation [24]. The ginsenoside $\mathrm{Rd}$ inhibited TNF- $\alpha$-induced expression levels of the COX-2 and iNOS genes in HepG2 cells [25]. Song et al. reported that the ginsenoside $R d$ is involved in the suppression of TNF- $\alpha$-induced NF-KB activation; this was shown in a gene reporter assay by a reduction in luciferase activity, which subsequently inhibited inducible NO synthase (iNOS) and COX-2 gene expression [25]. Kim et al. reported that the anti-inflammatory effects of ginsenoside Rd are due to the down-regulation of NF$\mathrm{KB}$ and the consequent expressional suppression of iNOS and COX-2. iNOS and COX-2 are known to play pivotal roles in the pathogenesis of acute and chronic inflammation, and thus, inhibition of the abnormal upregulation of iNOS and COX-2 provides a molecular basis for the therapeutic effects of ginsenoside $\mathrm{Rd}$ on inflammation and inflammatory diseases [26]. The mechanisms of ginsenoside Re may be associated with the inhibition of inflammatory mediator overproduction, including NO, malondialdehyde (MDA), interleukin (IL)$1 \beta$ and TNF- $\alpha$ [27]. The ginsenoside Re inhibited the phosphorylation of IL-1R-associated kinases (IRAK)-1 and inhibitor of NF-KB kinase subunit (IKK)- $\beta$ phosphorylation and the activation of NF-KB in LPSstimulated peritoneal macrophages, as well as the binding of Alexa Fluor 488-conjugated LPS to Toll-like receptor (TLR)4 on peritoneal macrophages transiently transfected with or without myeloid differentiation factor 88 (MyD88) siRNAs [28]. The inhibitory mechanisms of ginsenosides $\mathrm{Rd}$ and $\mathrm{Re}$ may be related to suppressing the cytokines, endotoxins and reactive oxygen activated by tumour promoters.

A small number of epidemiological studies have explored the effects of ginseng use on prevention of cancer $[29,30]$. The questionnaire used in the casecontrol studies described above was used to determine ginseng use in a cohort study involving 4634 people aged over 40 years [31]. However, the available evidence for the cancer preventive effects of ginseng preparations in humans is inconclusive, and further methodologically rigorous research is required.

In conclusion, this is the first report to find that the ethanol extract of ginseng berry inhibits tumour promotion by TPA following initiation with DMBA in ICR mouse skin. Two active components, ginsenosides $R d$ and $R e$, were subsequently isolated from the active fraction of the ethanol extract of ginseng berry.

\section{CONFLICT OF INTERESTS}

The authors declare that there is no conflict of interests regarding the publication of this paper.

\section{ACKNOWLEDGEMENTS}

This study was supported in part by High valueadded Food Technology Development Program, Ministry of Agriculture, Food and Rural Affairs (Anyang, Kyung-ki-do, South Korea).

\section{REFERENCES}

[1] Yasukawa K. Medicinal and edible plants as caner preventive agents. In: Drug discovery research in pharmacognosy. Eds. Vallisuta O, Olimat SM. InTech, Rijeka, 2012; 181-208.

http://dx.doi.org/10.5772/34545

[2] Yasukawa K. Edible and medicinal mushrooms as promising agents in cancer. In: Drug discovery and development From molecules to medicine. Eds. Vallisuta O, Olimat SM. InTech, Rijeka, 2015; 39-61.

http://dx.doi.org/10.5772/59964

[3] Bown D, Encyclopedia of herbs - \& their uses -, Dorling Kindersley, London, 1995; 355.

[4] Barnes J, Anderson LA, Phillipson JD. Herbal medicines. 3rd edition, Pharmaceutical Press, London, 2007; 325-336.

[5] Kim HJ, Kim P, Shin CY. A comprehensive review of the therapeutic and pharmacological effects of ginseng and ginsenosides in central nervous system. J Ginseng Res 2013; 37: 8-29.

http://dx.doi.org/10.5142/jgr.2013.37.8

[6] European Medicine Agency, Assessment report on Panax ginseng C.A. Meyer, radix. http://www.ema.europa.eu/docs/ en_GB/document_library/Herbal_-_HMPC_assessment_ report/2014/05/WC̄500167385.pdf.

[7] Christensen LP. Ginsenosides: chemistry, biosynthesis, analysis, and potential health effects. Adv Food Nutr Res 2007; 55: 1-99.

http://dx.doi.org/10.1016/S1043-4526(08)00401-4

[8] Chen X, Liu H, Lei X, Fu Z, Li Y, Tao L, Han R. Cancer chemopreventive and therapeutic activities of red ginseng. $J$ Ethnopharmacol 1998; 60: 71-78. http://dx.doi.org/10.1016/S0378-8741(97)00133-5

[9] Keum Y-S, Park K-K, Lee J-M, Chun K-S, Park JH, Lee SK, Kwon $\mathrm{H}$, Surh $\mathrm{Y}$-J. Antioxidant and anti-tumor promoting activities of the methanol extract of heat-processed ginseng. Cancer Lett 2000; 150: 41-48.

http://dx.doi.org/10.1016/S0304-3835(99)00369-9 
[10] Ko SK, Bae HM, Cho OS, Im BO, Chung SH, Lee BY. Analysis of ginsenoside composition of ginseng berry and seed. Food Sci Biotechnol 2008; 17: 1379-1382. http://agris.fao.org/openagris/search.do?recordID=KR200900 1089

[11] Yasukawa K, Takido M, Takeuchi M, Nakagawa S. Effect of chemical constituents from plants on 12-Otetradecanoylphorbol-13-acetate-induced inflammation in mice. Chem Pharm Bull (Tokyo) 1989; 37: 1071-1073. http://dx.doi.org/10.1248/cpb.37.1071

[12] Kasahara Y, Kumaki K, Katagiri S, Yasukawa K, Yamanouchi S, Takido M, Akihisa T, Tamura T. Carthami Flos extract and its component, stigmasterol, inhibit tumor promotion in mouse skin two-stage carcinogenesis. Phytother Res 1994; 8: 327-331. http://dx.doi.org/10.1002/ptr.2650080603

[13] Yasukawa K, Sun Y, Kitanaka S, Tomizawa N, Miura M, Motohashi S. Inhibitory effect of the Rhizomes of Alpinia officinarum on TPA-induced inflammation and tumor promotion in two-stage carcinogenesis in mouse skin. $J$ Nat Med 2008; 62: 374-378. http://dx.doi.org/10.1007/s11418-008-0243-2

[14] Yasukawa K, Okuda S, Nobushi Y. Inhibitory effect of gymnema (Gymnema sylvestre) leaves on tumour promotion in two-stage mouse skin carcinogenesis. Evidence-Based Complement Alternat Med 2014; 2014: 328684. http://dx.doi.org/10.1155/2014/328684

[15] Lu P, Yin Y. Pulsed electric field treatment combined with commercial enzymes converts major ginsenoside $\mathrm{Rb} 1$ to miner ginsenoside Rd. Innovat Food Sci Emerg Technol 2014; 22: 95-101. http://dx.doi.org/10.1016/j.ifset.2013.12.010

[16] Teng R, Li H, Chen J, Wang D, He Y, Yang C. Complete assignment of ${ }^{1} \mathrm{H}$ and ${ }^{13} \mathrm{C}$ NMR data for nine protopanaxatriol glycosides. Magn Reson Chem 2002; 40: 484-488. http://dx.doi.org/10.1002/mrc.1033

[17] Balkwill F, Mantovani A. Inflammation and cancer: back to Virchow? Lancet 2002; 357: 539-545. http://dx.doi.org/10.1016/S0140-6736(00)04046-0

[18] Scott KA, Moore RJ, Arnott CH. An anti-tumor necrosis factor-a antibody inhibits the development of experimental skin tumors. Mol Cancer Ther 2003; 2: 445-451. http://mct.aacrjournals.org/content/2/5/445.long

[19] Bowie A, O'Neill LA. Oxidative stress and nuclear factorkappaB activation: a reassessment of the evidence in the light of recent discoveries. Biochem Pharmacol 2000; 59: 1323. http://dx.doi.org/10.1016/S0006-2952(99)00296-8

[20] Pikarsky E, Porat RM, Stein I, Abramovitch R, Amit S, Kasem S, Gutkovich-Pyest E, Urieli-Shoval S, Galun E, Ben-Neriah $\mathrm{Y}$. NF-KB functions as a tumour promoter in inflammationassociated cancer. Nature 2004; 431: 461-466. http://dx.doi.org/10.1038/nature02924
[21] Mohan S, Epstein JB. Carcinogenesis and cyclooxygenase: the potential role of COX-2 inhibition in upper aerodigestive tract cancer. Oral Oncol 2003; 39: 537-546. http://dx.doi.org/10.1016/S1368-8375(03)00035-6

[22] Aggarwal BB, Gehlot P. Inflammation and cancer: how friendly is the relationship for cancer patients? Curr Opin Pharmacol 2009; 9: 351-369.

http://dx.doi.org/10.1016/j.coph.2009.06.020

[23] Wu CF, Bi XL, Yang JY, Zhan JY, Dong YX, Wang JH, Wang JM, Zhang R, Li X. Differential effects of ginsenosides on NO and TNF- $\alpha$ production by LPS-activated N9 microglia. Int Immunopharmacol 2007; 7: 313-320. http://dx.doi.org/10.1016/j.intimp.2006.04.021

[24] Jeong HG, Pokharel YR, Han EH, Kang KW. Induction of cyclooxygenase-2 by ginsenoside $\mathrm{Rd}$ via activation of CCAAT-enhancer binding proteins and cyclic AMP response binding protein. Biochem Biophys Res Commun 2007; 359: 51-56.

http://dx.doi.org/10.1016/j.bbrc.2007.05.034

[25] Song SB, Tung NH, Quang TH, Ngan NTT, Kim KE, Kim YH. Inhibition of TNF- $\alpha$-mediated NF-KB transcriptional activity in HepG2 cells by dammarane-type saponins from Panax ginseng leaves. J Ginseng Res 2012; 36: 146-152. http://dx.doi.org/10.5142/jgr.2012.36.2.146

[26] Kim DH, Chung JH, Yoon JS, Ha YM, Bae S, Lee EK, Jung KJ, Kim MS, Kim MK, Chung HY. Ginsenoside Rd inhibits the expressions of iNOS and COX-2 by suppressing NF-kB in LPS-stimulated RAW264.7 cells and mouse liver. J Ginseng Res 2013; 37: 54-63. http://dx.doi.org/10.5142/jgr.2013.37.54

[27] Paul S, Shin HS, Kang SC. Inhibition of inflammations and macrophage activation by ginsenoside-Re isolated from Korean ginseng (Panax ginseng C. A. Meyer). Food Chem Toxicol 2012; 50: 1354-1361.

http://dx.doi.org/10.1016/j.fct.2012.02.035

[28] Lee I-A, Hyam SR, Jang S-E, Han MJ, Kim D-H. Ginsenoside Re ameliorates inflammation by inhibiting the binding of lipopolysaccharide to TLR4 on macrophages. J Agric Food Chem 2012; 60: 9595-9602.

\section{http://dx.doi.org/10.1021/jf301372d}

[29] Yun TK, Choi SY. A case-control study of ginseng intake and cancer. Int J Epidemiol 1990; 19: 871-876. http://dx.doi.org/10.1093/ije/19.4.871

[30] Yun TK, Choi SY. Preventive effect of ginseng intake against various human cancers: a case-control study on 1987 pairs. Cancer Epidemiol Biomarkers Prev 1995; 4: 401-408. http://cebp.aacrjournals.org/content/4/4/401.long

[31] Yun TK, Choi SY. Non-organ specific cancer prevention of ginseng: a prospective study in Korea. Int J Epidemiol 1998; 27: $359-364$ http://dx.doi.org/10.1093/ije/27.3.359 